\title{
A Research for Feasibility Analysis and Model Building of e-Tourism Industrial Value Chain with Cooperation of Industry, Government and University in Taiwan
}

\author{
Hsu Shun-Fa ${ }^{1}$, Lee Yi-In² ${ }^{*}$, Hsu Ching-Tzu ${ }^{3}$, Chen Chih-Hua ${ }^{4}$ \\ ${ }^{1}$ Department of Information Management, Chung Chou University of Science and Technology; No. 6, Lane 2, \\ Sec. 3, Shanjiao Rd., Yuanlin City, Changhua County 510, Taiwan. \\ ${ }^{2}$ Department of Hospitality Management, Chung Chou University of Science and Technology; No. 6, Lane 2, \\ Sec. 3, Shanjiao Rd., Yuanlin City, Changhua County 510, Taiwan. \\ ${ }^{3}$ Trainee, Aviation Training Institute, Civil Aeronautics Administration, Ministry of Transportation and \\ Communications; No. 362, Bing-Jiang Street, Taipei 10594, Taiwan. \\ ${ }^{4}$ Department of Information Networking and System Administration, Ling Tung University; No.1, Lingtung \\ Rd., Taichung City 408, Taiwan.
}

* Corresponding author. Tel: 886-4-835-9000; email: yiin@gm.ccut.edu.tw Manuscript submitted May 20, 2019; accepted December 29, 2019.

doi: 10.17706/ijeeee.2020.10.2.135-144

\begin{abstract}
This paper investigates the technical resources of cooperation of industry, government and university, and how industrial value chains (IVC) in e-tourism industry develop in such collaboration. First, the chance of cooperation between small and medium enterprises (SMEs) in tourism industry and information technology developers were discovered inside the national industry policies of Taiwan, and local technological universities could play a key role inside as an official resource importer. Then, theoretical feasibility of industry-government-university cooperation in e-tourism and IVC were testified to build the core concept of e-tourism IVC model with cooperation of industry, government and university.

Furthermore, based on prospective framework in e-tourism, the research team, consisting of professionals in various fields, put the concept into practice by endeavoring to collaborate with enterprises in tourism and information and communication technology (ICT) industry. After complying with requirements of grant applying programs, the team acquired funds of 570,000 NTD from Ministry of Education (MOE), companies and universities, making this cooperation model preliminarily practical.

As stated above, e-tourism IVC model with cooperation of industry, government and university is an applicable university-industry cooperation (UIC) model technological universities can utilize to enhance competitiveness of ICT and tourism industries, as well as SMEs.
\end{abstract}

Key words: E-tourism, industrial value chain (IVC), cooperation of industry, government and university (I/G/U), location-based service (LBS), app development.

\section{Introduction}

Industrial patterns all over the world have changed a lot in this era of knowledge-based economies, globalization, and rapidly-changed technological progress. Narrowed division of labor in industrial value chains (IVC) and political uncertainty when concerning ideology both make international business more competitive.

Information and communication technology (ICT) hardware manufacturers and fabricators in Taiwan, 
with high percentage of small and medium enterprises (SMEs), face difficulties as smaller income growth of enterprises and production limitation of ICT hardware inside the state-of-the-art ICT industrial supply chain. Nevertheless, in the trend of rapidly growing 4G penetration, e-commerce, entertainment and service apps which develop swiftly, producing ICT industry a turning point.

Meanwhile, as consumption level, demand of product and service quality rise simultaneously when Taiwan steps into one of the developed countries, people pay much attention to economic growth related tourism industry. Total income of tourism industry increased to NTD 777 billion (4.45\% of GDP) at 2017 from 371.3 billion $(2.94 \%)$ at 2008 , meaning that the development of tourism industry in Taiwan should transform from pure quantitation-driven to quality-driven basis; thus, making income increase by quality enhancement. How to best exploit the strength of ICT industry to promote tourism industry and form the development chance of e-tourism, will be a challenging issue Taiwan should confront and solve.

From a superior viewpoint of national economic development policies, cooperation chances may be found from the supply and demand between ICT and tourism industries. Comparing that every single enterprise fight alone to solve the difficulty, ICT and tourism enterprises collaborate to reach better profit will be a much more effective way. Technological universities can play as an important bridge in between as universities possess technological capability to communicate with ICT industry and students to take internships in tourism enterprises.

Facing advantages as higher traveling demand, sophisticated ICT industrial chain, and powerful technological universities, how to build a suitable cooperation model is the main focus of this paper. Main objectives of this research are as follows:

1) To explore on the industrial applied value of e-tourism for applying ICT into tourism industry.

2) To investigate the feasibility on the IVC with cooperation of industry, government and university

3) To build a core concept of e-tourism IVC with cooperation of industry, government and university model, making this research be deemed as an initiation of future researches.

\section{Literature Review}

\subsection{E-Tourism and Location-Based Service}

E-tourism, also known as travel technology or e-travels, refers to the research field and the impacts of how ICT reshapes the development and management in the tourism industry (Buhalis and Peter 2005). [1] Ever since the emerging phase of ICT, airlines and hotels started the adoption process soon with the acquisition of computer reservation systems. The spread of internet from 1990s changed the information distributions between customers and enterprises, and started to reconfigure the structure of tourism sectors (Buhalis and Law 2008). [2]

Furthermore, due to the intangible and experiential nature of tourism products, explosive usage of social media is dramatically changing the way travelers think, search and behave towards the tourism products (Sigala, Christou, and Gretzel 2012). [3] Unlike one-way communication in most mass media channels, social media plays an important role in the tourism industry as two-way communication may cooperate to produce comments of tourism suppliers and destinations, which results in further outcomes.

Yang and Li (2008) pointed out Location-Based Service (LBS) is composed of positioning technique (by GPS) and information supply. [4] The definition of LBS is "Decide what to offer to every user by one's location. Combine mobile communication technique with GPS to provide the most suitable individual service for the user at one's location and satisfy one's need. (Ho, 2004) [5] There are three essentials of LBS: First, the terminal device should have wireless function. Second, it requires GPS technique. And the third is that the device can deliver or apply services.

Inventions on software and hardware will be needed when enterprises transform into e-tourism industry, 
especially for sightseeing crowds on the weekends. As smart phones and tablets widespread, tourists can download apps easily from clouds. Therefore, helping develop and utilize tourism navigation apps are necessary as these apps may enhance the satisfaction of tourists.

\subsection{University-Industry Cooperation (UIC)}

Information systems on smart phones indicate the model of information system continuance. Users' continuance intention of apps may be influenced by perceived usefulness of continued information system use, user satisfaction, and their confirmation of expectation from prior usage (Bhattacherjee, 2001a, 2001b). [6], [7] According to model of information system continuance theory from Bhattacherjee, navigation apps of tourism factories should be made with three criteria: perceived usefulness, user satisfaction, and confirmation of expectation, in order to be continuously used. Therefore, cultural and creative content should be added to improve the perceived usefulness of apps, and the products should meet the travelers' needs, etc.

Contents of tourism navigation apps can be diversified, but should be at least consisted of necessary information which tourists need for a trip. When developing navigation apps, tourism companies need to clarify that navigation apps are not their products but tools to cut down the navigation cost and gain more profit. Revenue comes still from their own tourism resources, services, and products. Interesting tourism navigation apps may not only attract tourists, but also help customize individual navigational needs of tourists.

For industry, new technics are keys for companies to grow and be competent. New technics may be produced by research and development (R\&D) of their own, or by cooperation in industry, between industry and other research center, and between industry and academia. University-Industry Cooperation (UIC) is considered the most important one among these options (Wainwright, 1988; Novozhilov, 1991; Chen, 1994; Wu, 1994) [8]-[11]; moreover, Rahm \& Crow (1988) and Chen (1990) treat UIC as one of the main factors influencing competitiveness of one country. [12], [13]

Theoretically, the cooperation between industry and universities are bilateral. Universities provide business philosophy and technology upgrade by forming strategic alliances or technology transfer, while industry offers internship chances and equipment to maximize benefits on both sides (Chen and Liao, 2017). [14] Most enterprises in the typical small open economy of Taiwan, face the extremely competitive pressures in the international market, and also have difficulties of cost and time constraints when investing in technological innovation.

Therefore, how to construct a cooperative innovation network of industry, government and universities to strategically use cooperation resources, and to overcome diseconomies of scale problems faced by small economies and SMEs in technological innovation is a critical issue (Liu, 1996) [15] Chou (2013) asserted that the transformation and upgrading of Taiwan's future industry must move from "Manufacturer Taiwan" to "Innovation Taiwan" or "Knowledge Taiwan", the strategy of UIC is an important cornerstone. [16]

In addition, Lee (1998) proclaimed that the joint R\&D of industry, government and universities is bound to become one of the important sources of industrial technology improvement in Taiwan. If Taiwanese companies would like to develop the technology ability; besides their own R\&D investment, they must establish a cooperative R\&D model between industry, government and universities, and use government-supported R\&D resources to help. [17] How to cooperate with the national economic development and the resources and technology of universities to create new opportunities for the industry is an urgent task for every enterprise (Lee, 2014) [18].

According to OECD, there are four main advantages concerning UIC talent cultivation from the perspective of students and enterprises: (1) Provide high quality learning environment, allowing students to master latest practical skills, working methods and techniques from trainers or instructors, which 
improving their soft skills; (2) Enhance bilaterally information flow between potential employers and employees, allow subsequent talent recruitment to be more efficient and less costly. (3) Companies provide internship or apprenticeship training, and release the signal of the labor market value of its vocational education and training program. (4) In the internship, the students bring productive contributions to the company. In other words, the cultivation of UIC talents brings considerable short-term and long-term benefits to students, employers and society. (Hoeckel, 2008) [19] (See Table 1)

Table 1. Benefits of UIC Talent Cultivation

\begin{tabular}{|c|c|c|}
\hline & Short-term benefits & Long-term benefits \\
\hline Individual & $\begin{array}{l}\text { Employment chances } \\
\text { Earning levels } \\
\text { Work satisfaction } \\
\text { Drop out less likely from vocational than general } \\
\text { courses (US data) }\end{array}$ & $\begin{array}{l}\text { Flexibility and mobility } \\
\text { Lifelong learning (more likely to receive training } \\
\text { and upgrade skills later in life) }\end{array}$ \\
\hline Employer & $\begin{array}{l}\text { Higher productivity from well trained workforce } \\
\text { Saved costs from recruiting external skilled workers } \\
\text { (incl. time for integration and risk of hiring a person } \\
\text { not known to the company) }\end{array}$ & $\begin{array}{l}\text { Supply benefits (e.g. image improvement) } \\
\text { Less turnover (no need for retraining of new } \\
\text { workers) }\end{array}$ \\
\hline Society & $\begin{array}{l}\text { Saved expenses for social benefits (unemployment } \\
\text { as consequence of failed transition from education } \\
\text { to work) }\end{array}$ & $\begin{array}{l}\text { Externalities from productivity gain due to better } \\
\text { education } \\
\text { Increase in tax income from higher earnings }\end{array}$ \\
\hline
\end{tabular}

Source: OECD(2010),Costs and Benefits in Vocational Education and Training.

Wen, Hsu and Wu (2006) discussed the scope and methods of the UIC in the public sector in "the study of the administrative organization and resource integration of the vocational and technical schools." MOE, the Ministry of Science and Technology (MOST) and the Ministry of Economic Affairs (MOEA) have a number of plans and laws related to UIC in order to integrate industry and academic resources and promote cooperation in Taiwan. [20]

Department of Industrial Technology (DoIT) of MOEA (2006) investigated different UIC benefits required from different motives of UIC participating in the White Paper on Industry and Technology. Therefore, for universities, developers, industry and the government, there are different levels of benefits and incentives of UIC at the financial, economic, technical and political levels. [21] Liu, Chung, Lin and Chi (2016) concluded the roles of ministries in the field of innovation and UIC with national UIC consulting and supporting policy are: 1). MOE: Promoter of knowledge flow, 2). MOST: Promoter of innovative knowledge 3. MOEA: Promoter of enhancing the value of industry and products. [22]

\subsection{Industrial Value Chain (IVC)}

Based on Michael Porter's "value chain", the "industrial value chain" is supplemented by the concept of upstream and downstream supply chain and enterprise cooperation, forming a cooperative value chain that spans between individual firms, upstream and downstream of the industry. Huang (2007) mentioned that although the term IVC is abstract but its meaning is widely used and analyzed in various fields. [23] The concept of value chain was first proposed by international strategy management master Michael E. Porter 
(1985). From the perspective of business management, he believes that customers, suppliers, and companies create value from a variety of independent and interrelated types of basic and auxiliary activity chains, including independent parts such as product design, production, marketing, transportation, and related support operations. Besides, Porter pointed out that different companies in the same industry may have different value chains, and the industrial structure will affect the IVC. The value chain proposed by Michael Porter divides the activities of the enterprisers into two categories: major activities including in-plant logistics operations, production operations, off-site logistics operations, marketing and sales, and services, support activities including procurement, technology development, and human resource management. Marginal profit is created by the cooperation of supporting activities and major activities. In short, the value chain is a series of activities that produce product or value. Many economic activities have value chains. Each value activity in the value chain affects the ultimate value created by the enterprise. [24]

The original definition of value chain was mainly for a single enterprise. However, as professional division of labor and the global operation management emphasized in recent years, enterprises have to be competent and link to upstream and downstream manufacturers in order to make profits. The main points of supply chain management are to integrate and use the value chains of upstream and downstream enterprises, quickly respond to the market, and obtain profits. Therefore, the management of a supply chain is like tying together the value chains of upstream and downstream enterprises, and form the concept of the IVC. Generally speaking, the IVC refers to the processes of value formation and enhancement from vertical division of labor of upstream suppliers, mid-stream manufacturers, downstream vendors and even final use of consumers (Huang, 2007).

In order to improve product quality and customer satisfaction and form the most efficient value chain, enterprises exploit professional division of labor and vertical integration of the value chain from the production line to consumers. (Lai, 2016) [25] The focus of the IVC extends to the value creation activities of the entire industry, expecting to reduce duplicative investment, enhancing cooperation and competitiveness, sharing economic interests, and thus achieving the realm of industrial coexistence and common prosperity (Lin, 2018) [26].

\section{Core Concept of e-Tourism IVC Model}

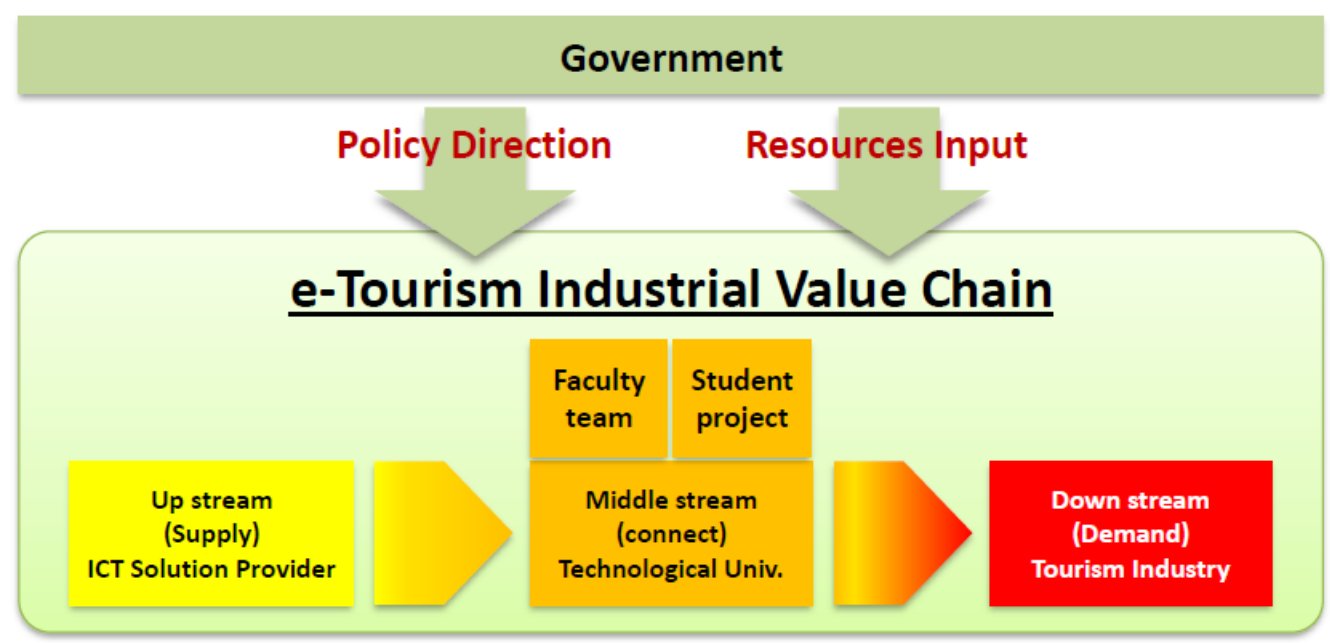

Fig. 1. Core concept of e-Tourism industrial value chain model.

Based on industry-government-university cooperation, IVC, and the demand of e-tourism, this paper built the core concept of e-tourism IVC model in the methodology of importing ICT tools in applied tourism 
scenario. The model shows as Fig. 1 below. In the framework of industry-government-university cooperation, the role of public sector is mainly in policy planning and funding. Technological universities of the academia bridge upstream ICT suppliers and downstream tourism demanders. Professionals and students in universities participate in lots of e-tourism UIC activities, such as specific projects, internships, visiting, and competitions. For instance, they visit tourism companies to collect materials, plan navigation scripts and visual communication design, develop an app with industrial context, and create a related tourism marketing value through the app development platform provided by ICT companies. This win-win situation of industry, government, and university is then established.

\section{Discussion}

\subsection{Verify Preliminarily Feasibility of the Core Concept of e-Tourism IVC Model as Acquiring Grants from MOE}

Based on prospective framework in e-tourism, this paper established the core concept of e-tourism IVC model practically by seeking connections of cooperative enterprises and acquiring grants from different projects. The research team, consisting of professionals in various fields, put the concept into practice by endeavoring to collaborate with enterprises in tourism and ICT industry.

Beside the research strength of university and industry, the government role as policy maker and resource importer is considered significant at the beginning phase of an influential UIC program in the e-tourism IVC model. As the team tried to verify the practicability of the core concept of e-tourism IVC model, they conducted a pilot project of this concept. After integrating thoughts and proposals, and complying with requirements of grant applying programs of MOE and MOEA, the team acquired grants in topic "When App Appear Among the Cultural and Creative Industries and Tourism Factory - The Technological Navigation App System Development Plan in Taiwan Glass Gallery" from the granting program "MOE Industry-Academy Cooperation - branch of cultural creation and digital service." By grants of 240,000 NTD from enterprises, 270,000 NTD from MOE, and 60,000 NTD from the university, this cooperation model was put into practice preliminarily and the feasibility was verified. (Hsu, Lin, Cao and Lin, 2013) [27]

\subsection{Enhance Technology Progress and Tourism Service Level by Apps Developed from UIC for a Tourism Factory-Taiwan Glass Gallery}

Taiwan Glass Gallery, located in the central part of the island, receives about 100 thousand visitors monthly. Before this UIC program, the site provided navigation menus, quite a few layout graphic kanbans, and directional signs and random-play explanation videos for visitors. Also, many tour guides were hired to provide narration services. Group visitors could reserve navigation service in advance, but when an excessive number of group visitors, still only a few tourists could hear narration services as they followed closely with tour guides, and others could just barely hear the voice navigation without corresponding image and text impressions. As individual visitors were unable to acquire navigation due to the lack of tour guides, the gallery often received individual guests' complaints. When visitors could not appreciate the beauty of glass art craft and high value of glass merchandise by good navigation services, they would not purchase glass art craft in tourism factory, which causing massive loss of tourism revenues for Taiwan Glass Gallery since they did not charge admission.

For the goal of improving recreation experience of the tourists in Taiwan Glass Gallery, the app cooperative development project making six indoor POIs (Point of Interest) interactive apps and one outdoor LBS app was carried out. The apps in the project used hybrid app development way: Using HTML 5 programming language of Web App to develop at first, adding some proportion of Native App; in the end, packing it with Native App to execute easily with fingers. 
In the meanwhile, this project also developed another outdoor LBS app, allowing visitors to download for traveling route planning and map navigation before the trip. The research team designed four main features of the outdoor LBS app to satisfy the need of tourists. 1) Show the basic information of the destinations; 2) Show the basic information of near destinations to help tourists plan their trip routes; 3) Tourists can use Google Map to navigate; 4) Share information of app to community platform via LINE, Facebook, Gmail, etc. (Hsu, Lee, Lan, Hsu and Wang, 2015) [28].

\section{Conclusions and Recommendations}

Established on literature reviews and execution of e-tourism IVC with cooperation of industry, government and university, preliminary conclusions of the paper are as follow:

1) With higher percentage of smart phone usage and the tourism industry contributed GDP growth, e-tourism becomes more essential nowadays. This study focuses on the industrial value of e-tourism by applying ICT to tourism field. Especially apps with LBS and interactive functions are important ICT execution in tourism industry.

2) This study successfully helped the company acquiring grants from government and technological assistance of technological universities in the way of combining the core concept and tourism policies, proving this core concept feasible in industry.

3) This study describes how to build a core concept of e-tourism IVC with cooperation of industry, government and university. Already validated this core concept, this research can be deemed as an initiation of future researches.

\section{Conflict of Interest}

The authors declare no conflict of interest.

\section{Author Contributions}

Shun-Fa Hsu: Leader of e-tourism research team, host related government, university and industrial cooperative projects, conducted this research, establish this conceptual framework and wrote this paper mainly.

Yi-In Lee: Senior consultant of e-tourism research team and co-host related government, university and industrial cooperative projects.

Ching-Tzu Hsu: Co-wrote this paper and translated to English.

Chih-Hua Chen: Member of e-tourism research team, co-host university training and prompting program of grant from Ministry of Education (MOE), pilot practice this conceptualframework.

\section{References}

[1] Buhalis, D., \& O'Connor P. (2005). Information communication technology revolutionizing tourism. Tourism Recreation Research, 30(3), 7-16.

[2] Buhalis, D., \& Law, R. (2008). Progress in information technology and tourism management: 20 years on and 10 years after the internet - The state of e-tourism research. Tourism Management, 29, 609-623.

[3] Sigala, M., Christou, E., \& Gretzel, U. (2012). Social Media in Travel, Tourism and Hospitality: Theory, Practice and Cases. Ashgate Publishing, Ltd.,

[4] Yang, M. M., \& Li, M. H. (2008). A study of the touring activity using location-based service in Northern Taiwan. Hwa Kang Geographical Journal, 21, 115-135.

[5] Ho, M. S. (2004). Market Segmentation and the Intention of Using Mobile Value-Added Services. Institute 
of Telecommunications Management, Unpublished master thesis, National Cheng Kung University, Taiwan.

[6] Bhattacherjee, A. (2001a). Understanding information systems continuance: An expectation-confirmation model. MIS Quarterly, 25(3), 351-370.

[7] Bhattacherjee, A. (2001b). An empirical analysis of the antecedents of electronic commerce service continuance. Decision Support Systems, 32(2), 201-214.

[8] Wainwright, M. S. (1988). Industry-university of new south wales cooperative program in chemical engineering. Chemical Engineering in Australia, 13(2), 16-18.

[9] Novozhilov, Y. V. (1991). University-industry cooperation in eastern europe: the experience of some advanced universities in the USSR. International Journal of Technology Management, 6(5), 469-477.

[10] Chen, E. Y. (1994). The evaluation of University-Industry Technology in Hong Kong. Technovation, 449-459.

[11] Wu, F. S. (1994). A study for model and trend of technical cooperation. Proceedings of the 3rd Industry Management Conference. Taipei: Fu Jen Catholic University.

[12] Rahm, D. B., \& Crow, M. (1988). Domestic technology transfer and competitiveness: An empirical assessment of roles of University and Governmental R \& D Laboratories. Public Administration Review, 969-978.

[13] Chen, K. T. (1990). Harnessing University research for competitiveness, industry support. IEEE Spectrum, 27(10), 73-76.

[14] Chen, H. T., \& Liao, H. G. (2017). The reflection and suggestions for university-industry cooperation. Taiwan Education Review Monthly, 6(8), 37-41.

[15] Liu, J. L. (1996). Looking at Taiwanese scientific and technological competitiveness from the 1996 Global Competitiveness Report. National Competitiveness Series References 2, Printed by the Science and Technology Information Center of the National Science Council of the Executive Yuan.

[16] Chou, T. T. (2013). Taiwan's strategic model for promoting university-industry cooperation: University and industry cooperative R\&D and talent cultivation. Journal of Chaoyang University, 18, 85-109.

[17] Lee, J. F. (1998). Industry-University-Research Cooperation Innovation and National Competitiveness.

[18] Lee, Y. Y. (2014). 2014 Special Issue of High-Quality Research and Development Results Marketing of the Ministry of Education. Taipei: Ministry of Education.

[19] Hoeckel, K. (2008). Costs and Benefits in Vocational Education and Training. OECD, EDU/EDPC/CERI(2008).

[20] Wen L. Y., Hsu, S. F., \& Wu, J. Y. (2006). A research on the administrative organization and resource integration of the vocational schools promoting cooperation. Proceeding of Seminar on SMEs' Development and Science and Technology Innovation across the Taiwan Strait. Beijing Forestry University and Changhua University of Education Co-host. Beijing: China.

[21] Department of Industrial Technology (DoIT) of Ministry of Economic Affairs. (2006). 2006 Industrial Technology White Paper. Taiwan Economic Research Institute Publishing.

[22] Liu, S. C., Chung, J. C., Lin Y. J., \& Chi, Y. J. (2016). A discussion on the university-industry cooperation model for university. Journal of Chaoyang University, 21, 57-71.

[23] Huang, Y. H. (2007). A Preliminary Analysis of the Causes of the Movement of Taiwan's Industrial Value Chain. Taiwan Economic Research Institute.

[24] Porter, M. E. (1985). Competitive Advantage. Free Press, New York.

[25] Lai, C. C. (2016). A research on the relationship among network embedded, relational capital, value co-creation and corporate cooperation performance: An empirical analysis based on the advertising industrial value chain. Chinese Innovation and Development Journal, 4(1), 52-69. 
[26] Lin, L. Y. (2018). Industrial value chain division of coexistence and common prosperity. Economic Daily / Management Outpost.

[27] Hsu, S. F., Lin, C. S., Cao, F. P., \& Lin C. C., (2013). When app appears among the cultural and creative industries and tourism factories - The technological navigation App system development plan in Taiwan Glass Gallery. Proceeding of Conference Culture and Computer Science 2013.

[28] Hsu, S. F., Lee, Y. I., Lan M. Y., Hsu C. Z., \& Wang, C. H. (2015). Technological navigation apps development project for tourism factories: Taiwan glass gallery as an example. Proceeding of International Conference on Innovation and Management (IAM2015S). Sapporo/ Japan.

Copyright (C) 2020 by the authors. This is an open access article distributed under the Creative Commons Attribution License which permits unrestricted use, distribution, and reproduction in any medium, provided the original work is properly cited (CC BY 4.0).

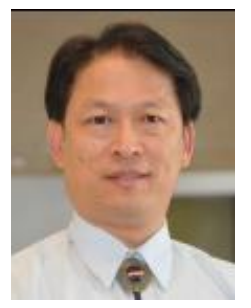

Shun-Fa Hsu was born in Chiayi Taiwan. He has completed the doctoral degree of business education from National Changhua University of Education (NCUE), Taiwan. He is the director of Intelligent Cloud-Computing \& Big-Data Center, and director of Innovation \& Incubation Center, and associate professor at the Dept. of Information Management, Chung Chou University of Science and Technology (CCUT) in Taiwan. His research interests focus on business education, e-commerce, app development, intelligent cloud-computing, enterprise diagnosis etc.

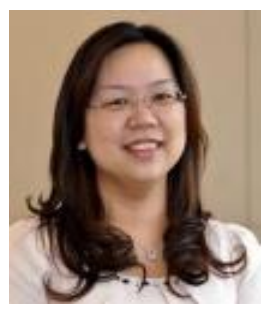

Yi-In Lee is an associate professor of the Department of Hospitality Management at the Choung Chou University of Science and Technology. She is also the director of the Marketing \& Public Opinion Survey Center and the chief consultant of Intelligent Cloud-computing \& Big-data Center. She used to be the chairperson of the Department of Creative Fashion Design and Management/ Director of Personnel/ Director of Operating Center/ Assistant professor of the department of Information Management/ Lecture of the department of International Trade. Her bachelor's degree and master's degree are in Statistics from the Fu-Jen Catholic University. Her doctoral degree from the National Yunlin University of Science and Technology is in Management, specializing in Organizational Behavior and Human Resource Management. She dedicates her interest in the researches of Customer Relationship Management, Big Data Analysis, Human Resource Development. She has published over 20 papers in international journals and conference proceedings and hosted over 50 projects (more than 20 million NT dollars) in the past decade. Besides, she is the member of audit committee of Talent Quality Management Systems (TTQS), one project of Workforce Development Agency, Ministry of Labor, R.O.C., which assists institutions and training entities raising quality of training programs.

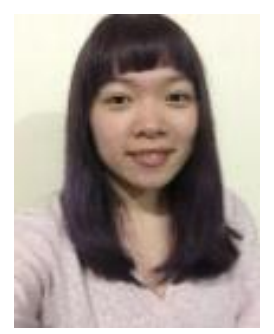

Ching-Tzu Hsu was born in Chunghwa, Taiwan. She graduated with a bachelor degree from the Department of Geography, National Taiwan University, Taipei, Taiwan at 2016. Her major field of study is geography, aviation and aviation control. She worked for Academia Sinica of Taiwan as part-time job since 2014 and became a Research Assistant from to 2016 to 2018. Now she works as a training Air Traffic Controller at Taipei. 
Chih-Hua Chen was born in Taichung. She earned the doctoral degree that focuses on the field of education from National Changhua University of Education in Taiwan in 2001. She had been a teacher in a junior high school for about 6 years (1991-1997). She is Dean of Career Development Office and asst. professor at the Dept. of Information Networking and System Administration, Ling Tung University in Taiwan.

Her research interests focus on creative thinking, e-commerce, supply chain \& customer relationship management etc. 